\title{
Is there a link between cot death and child abuse?
}

\author{
JACQUELINE ROBERTS, JEAN GOLDING, JEAN KEELING, BETTINE SUTTON, \\ MARGARET A LYNCH
}

\begin{abstract}
Forty five babies delivered in Oxford obstetric units who subsequently died unexpectedly in infancy were compared with 134 controls matched for maternal age, social class, parity, and year of birth to see whether five factors identified in an earlier study as predictive of subsequent child abuse would also predict the sudden infant death syndrome. Epidemiological findings had suggested certain similarities between the two events. In contrast with babies who were abused, four of the five factors did not distinguish between babies who died suddenly and unexpectedly and their controls, but there was a slight increase in the proportion of mothers of babies who died suddenly and unexpectedly for whom nursing staff thought that support and advice on feeding the baby were needed.

Factors predictive of child abuse did not predict
\end{abstract} sudden infant death in this study.

\section{Introduction}

Two studies have shown an increased postneonatal death rate among the siblings of abused children, ${ }^{2}$ but whether this excess mortality was a result of an excess in the sudden infant death syndrome was not clear. A recent study from Sheffield

Park Hospital for Children, Oxford OX3 7LX

JACQUELINE ROBERTS, MA, MSC, research social worker

Department of Child Health, University of Bristol, Bristol BS1 5QD JEAN GOLDING, MA, PHD, Wellcome Trust senior lecturer

John Radcliffe Maternity Hospital, Oxford

JEAN KEELING, MRCS, MRCPATH, consultant paediatric pathologist

Unit of Clinical Epidemiology, University of Oxford

BETTINE SUTTON, research assistant

Guy's Hospital Medical School, London SE1 9RT

MARGARET A LYNCH, MD, MRCP, senior lecturer in community paediatrics

Correspondence to: Mrs J Roberts, 15 Offley Road, London SW9 0LR. suggested that child abuse or neglect may be a contributory factor in about $10 \%$ of infant deaths presenting to the pathologist as sudden or unexpected. ${ }^{3}$

About half of all postneonatal deaths in this country are sudden and unexpected and in many of these postmortem examinations fail to identify a cause of death with certainty. Pathologists are unlikely always to be able to distinguish those infants who have been smothered from those who have died suddenly and unexpectedly from an unexplained natural cause. There are isolated reports of parents of infants whose deaths have been considered to be typical of sudden infant death syndrome deaths who have subsequently admitted to smothering their babies.

Epidemiological studies have suggested that there are associated factors common to both child abuse and the sudden infant death syndrome. Both events have been shown to occur more often with low maternal age, high birth order, low social class, and illegitimacy ${ }^{4}$; they are also associated with specific abnormalities of pregnancy, ${ }^{6}{ }^{7}$ preterm delivery, ${ }^{5}{ }^{7-9}$ and growth retardation. ${ }^{5} 7$ Thus there is circumstantial evidence that the sudden infant death syndrome may be a consequence of child abuse. In this study we examined whether other factors manifest during pregnancy and the early neonatal period, and known to be associated with child abuse, ${ }^{5}$ might also predict the sudden infant death syndrome; such factors could then be used to identify neonates at risk of the sudden infant death syndrome and might form the basis of intervention programmes aimed at reducing infant mortality.

\section{Subjects and methods}

We selected infants for study from all those born in Oxford obstetric units who died aged between 8 days and 2 years in 1971-6. The deaths were all sudden, unexpected, and referred to a coroner. Infants were included in the study if examination of any clinical notes, the postmortem reports, and (if possible) any histological material did not show any evidence of disease sufficient to explain death. ${ }^{10}$

As the purpose of the study was to test whether obstetric notes could be used to predict cases of the sudden infant death syndrome in the way that they had been shown to predict child abuse, we used the same method as in our study on prediction of child abuse. ${ }^{5}$ Crucial to this method were the detailed nursing and clinical notes available in Oxford obstetric units. 
For each infant studied who had died suddenly and unexpectedly we selected three controls from the same population, matched for year of delivery, social class, maternal age, parity, and civil state of the mother. The notes were scrutinised without knowledge of the subsequent fate of the infant. All obstetric and nursing notes for each group of four (case and three controls) were examined and a standard form completed for each. A particular search was made to see whether: (1) the mother was under 20 at the birth of her first child; (2) entries in the antenatal notes described emotional disturbance (the definition was not restricted to formal psychiatric illness but aimed at including any written evidence of psychological or emotional disturbance); (3) the mother or family had been referred to the medical social work department in the maternity hospital during either the study pregnancy or the neonatal period; (4) the baby had been admitted to a special care baby unit; or (5) in any records hospital staff had expressed concern about the ability of either parent to meet the child's physical or emotional needs. This sort of concern was usually recorded in the nursing notes but was occasionally found in the social workers' records.

Validation-When we designed this study initially to assess factors predicting the sudden infant death syndrome we assumed that cases of child abuse would segregate on the five factors described above, even when maternal age, parity, social class, and civil state were taken into account. (In the study of factors predicting child abuse we used "next birth" controls..$^{5}$ ) Obviously, if this assumption were wrong, the design of the whole study would not be viable. Each infant included in the first study who had subsequently been abused, as defined elsewhere, ${ }^{5}$ was therefore compared with three controls selected in the way described above for the present study. Clearly, this could not be conducted blind, but the possibility of bias was small as the information sought was objective-for example, whether the baby was admitted to a special care baby unit or whether there was an index card for the family in the maternity social work department, indicating referral to that department. Any written concern about parenting ability was recorded verbatim and not interpreted.

Statistical analysis-For each set of results, significance was tested with both a $2 \times 2 \%^{2}$ test with Yates's correction and the test using matched groups of four as described by McNemar. ${ }^{11}$ As the results with both methods were very similar, only the significance based on the $\%^{2}$ test is presented here.

\section{Results}

Validation study-Fifty infants had subsequently been abused. For them 146 controls were chosen (three controls for each of 48 abused children, one each for two others). There were eight cases in which a match was impossible: in each of these, women as close to the abusing mother in age, parity, social class, and civil state were chosen. Table I compares abused infants with their controls for social class, maternal age, and parity. There were no significant differences between the two groups. Table II compares the incidence of the five predictive factors in abused children and their controls. Because of the method of selection of controls there was no longer an

TABLE I-Comparison of maternal age, parity, and social class between infants who were abused or who died suddenly and unexpectedly (SIDS) and their matched controls

\begin{tabular}{|c|c|c|c|c|}
\hline \multirow[b]{2}{*}{ Matching factor } & \multicolumn{4}{|c|}{ No $\left({ }^{\circ} 0\right)$ of: } \\
\hline & $\begin{array}{l}\text { Abused } \\
\text { infants } \\
(n=50)\end{array}$ & $\begin{array}{l}\text { Matched } \\
\text { controls } \\
(n=146)\end{array}$ & $\begin{array}{c}\text { Infants } \\
\text { with SIDS } \\
(\mathrm{n}=45)\end{array}$ & $\begin{array}{l}\text { Matched } \\
\text { controls } \\
(\mathrm{n}=134)\end{array}$ \\
\hline \multirow[t]{2}{*}{$\begin{array}{l}\text { Social class: } \\
\text { I and II } \\
\text { III } \\
\text { IV } \\
\text { V } \\
\text { Armed forces } \\
\text { Unemployed/unsupported }\end{array}$} & $\begin{array}{r}1(2) \\
6(12) \\
15(30) \\
9(18) \\
7(14) \\
12(24)\end{array}$ & $\begin{array}{l}7(5) \\
25(17) \\
40(27) \\
26(18) \\
17(12) \\
31(21)\end{array}$ & $\begin{array}{r}6(13) \\
16(36) \\
8(18) \\
4(9) \\
3(7) \\
8(17)\end{array}$ & $\begin{array}{l}18(13) \\
47(35) \\
24(18) \\
12(9) \\
12(9) \\
21(16)\end{array}$ \\
\hline & \multicolumn{2}{|c|}{ NS } & \multicolumn{2}{|c|}{ NS } \\
\hline \multirow[t]{2}{*}{$\begin{array}{l}\text { Maternal age: } \\
\quad=20 \\
>20\end{array}$} & $\begin{array}{l}10(20) \\
40(80)\end{array}$ & $\begin{array}{r}31(21) \\
115(79)\end{array}$ & $\begin{array}{l}10(22) \\
35(78)\end{array}$ & $\begin{array}{r}31(23) \\
103(77)\end{array}$ \\
\hline & \multicolumn{2}{|c|}{ NS } & \multicolumn{2}{|c|}{ NS } \\
\hline \multirow[t]{2}{*}{$\begin{array}{c}\text { Parity: } \\
0 \\
1 \\
2-3 \\
\geqslant 4\end{array}$} & $\begin{array}{r}19(38) \\
17(34) \\
10(20) \\
4(8)\end{array}$ & $\begin{array}{l}61(42) \\
48(33) \\
25(17) \\
12(8)\end{array}$ & $\begin{array}{r}19(42) \\
14(31) \\
7(16) \\
5(11)\end{array}$ & $\begin{array}{l}58(43) \\
40(30) \\
21(16) \\
15(11)\end{array}$ \\
\hline & \multicolumn{2}{|c|}{ NS } & \multicolumn{2}{|c|}{ NS } \\
\hline
\end{tabular}

TABLE II-Number ( $\%)$ of abused infants and matched controls to have factors predictive of child abuse

\begin{tabular}{lccc}
\hline \multicolumn{1}{c}{ Factor } & $\begin{array}{c}\text { Abused } \\
\text { infants } \\
(\mathrm{n}=50)\end{array}$ & $\begin{array}{c}\text { Matched } \\
\text { controls } \\
(\mathrm{n}=146)\end{array}$ & p value \\
\hline Mother <20 at birth of first child & $25(50)$ & $69(47)$ & $\mathrm{NS}$ \\
Emotional disturbance & $23(46)$ & $20(14)$ & $<0.0001$ \\
Referral to social worker & $29(58)$ & $20(14)$ & $<0.0001$ \\
Admission of baby to a special care baby unit & $21(42)$ & $25(17)$ & $<0.001$ \\
Concern over parental ability & $22(44)$ & $18(12)$ & $<0.0001$ \\
\hline
\end{tabular}

TABLE III-Number $(\%)$ of sudden infant deaths (SIDS) and their matched controls to have factors predictive of child abuse

\begin{tabular}{lccc}
\hline \multicolumn{1}{c}{ Factors } & $\begin{array}{c}\text { Infants } \\
\text { with } \\
\text { SIDS } \\
(\mathrm{n}=45)\end{array}$ & $\begin{array}{c}\text { Matched } \\
\text { controls } \\
(\mathrm{n}=134)\end{array}$ & p value \\
\hline Mother 20 at birth of first child & $19(42 \cdot 2)$ & $55(41 \cdot 0)$ & NS \\
Emotional disturbance & $10(22 \cdot 2)$ & $20(14 \cdot 9)$ & NS \\
Referral to social worker & $7(15 \cdot 6)$ & $26(19 \cdot 4)$ & NS \\
Admission of baby to special care baby unit & $10(22 \cdot 2)$ & $22(16 \cdot 4)$ & NS \\
Concern over parental ability & $11(24 \cdot 4)$ & $13(9 \cdot 7)$ & 0.05 \\
\hline
\end{tabular}

association between child abuse and the age at which the mother had her first child but there were highly significant differences between abusing families and control families for each of the other four predictive factors.

Infants who died suddenly compared with controls-The 45 infants who died suddenly and unexpectedly in infancy were compared with 134 controls. There were no significant differences between the two groups on the criteria for matching (table I). Table III compares the two groups for each of the five factors predictive of child abuse. We did not find any significant difference between them in respect of maternal age at first pregnancy, documented emotional disturbance, referral to a social worker, or admission of the infant to a special care baby unit. Concern had, however, been expressed in the records over the parents' ability to cope with the child's physical or emotional needs in $11\left(24^{\circ}\right)$ of the infants who subsequently died suddenly and unexpectedly compared with $13\left(10^{\circ}\right)$ of the matched controls. Concern was expressed in the notes in various ways. In babies who died suddenly most of the concern referred to the mother's ability to feed the baby satisfactorily -for example, "Mother unsure about feeding; baby awake most of night through lack of food," and "Father of baby died shortly after conception; mother needs help with breast feeding and is upset about having to stay in hospital." Similar concern was, however, noted for some controls-for example, "Mother needs help with breast feeding, very unsure." Other problems also caused concern: "Mother very depressed, for careful observation, social worker asked to watch her" (baby who died suddenly), and "Termination requested originally; psychiatric problems? Medical social worker wondered whether mother would be aggressive towards baby" (control).

Summation of factors-In our earlier study, ${ }^{5}$ which attempted to predict child abuse, $35\left(70^{\circ}\right)$ of the 50 infants subsequently abused had at least two of the five predictive factors compared with only five $\left(10^{\circ}\right)$ of the randomly chosen control group. When the abused infants were matched with controls as described here, $37\left(25^{\prime \prime}{ }_{0}\right)$ of the control group also scored two or more factors; the difference, however, between the 50 abused infants and their controls was still highly significant $(p<0.0001)$. Examination of the histories of the babies who died suddenly and unexpectedly showed that $15(33 \%)$ had had two or more adverse factors compared with $35\left(26^{\circ}\right)$ of their matched controls. The difference between the two groups was not significant. Extension of the analysis to look at the number of infants who died suddenly with three or more adverse factors, however, identified eight $\left(18^{\circ}\right)$ compared with seven $\left(5^{\circ}{ }_{0}\right)$ of the matched controls. The difference just reached significance $(p<0.05)$. As it was found after a deliberate search for significant differences its interpretation is difficult.

\section{Discussion}

This study was designed to test whether those factors identifiable in the perinatal period and predictive of child abuse and neglect could also predict the sudden infant death syndrome. 
The search through the maternity notes of the infants who subsequently died suddenly and unexpectedly in infancy and their controls was conducted blind, and these results are therefore not biased by any subjectivity on the part of the researcher. Five factors were examined, but only one of them discriminated between those who died suddenly and their matched controls - namely, a record of concern about maternal ability to care for their babies made by midwives in the early neonatal period. Perhaps these mothers even at this early stage were reacting to abnormal responses in the baby.

After a deliberate search for significant differences, however, more sudden infant deaths than expected had three or more predictive factors, but whether this can be interpreted as evidence of child abuse contributing to sudden infant death in a small number of cases or whether it is a spurious statistical artefact requires elucidation from a larger study.

Important negative findings from this study were that the mothers of babies who died suddenly and unexpectedly were not more likely than their matched controls to have a history of psychiatric or emotional disturbance or to have been referred for any reason to the maternity hospital social worker during pregnancy or the neonatal period.

This research was supported by the Department of Health and
Social Security through a grant to JR. JG was supported by a Wellcome Trust senior lectureship. We are grateful to Miss Yasmin Iles for typing this report.

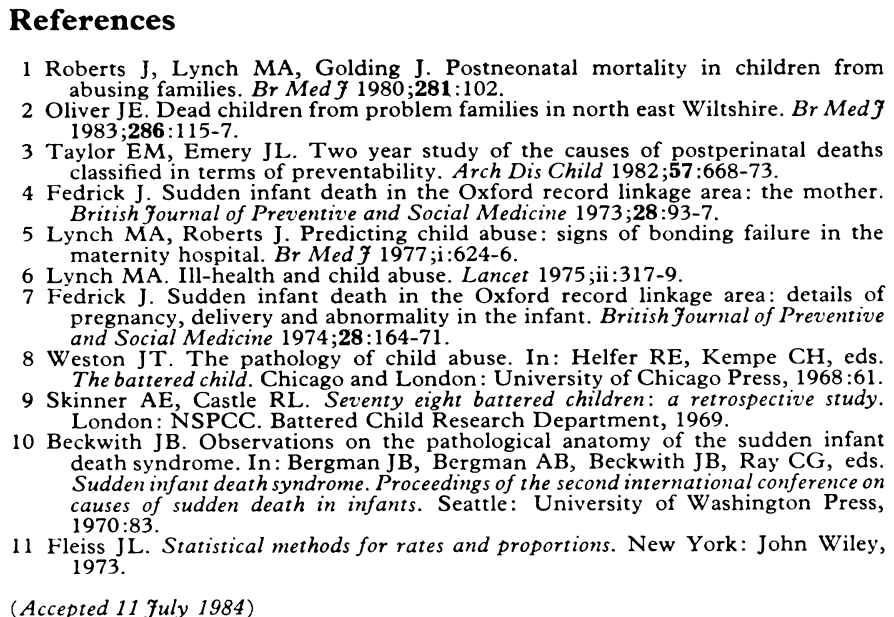

(Accepted 11 fuly 1984)

\title{
Lower cranial nerve motor function in unilateral vascular lesions of the cerebral hemisphere
}

\author{
ERNEST W WILLOUGHBY, NEIL E ANDERSON
}

\begin{abstract}
Motor function subserved by cranial nerves $V$, VII, $X$, $X I$, and XII was assessed in 100 patients with hemiparesis due to a unilateral vascular lesion of the cerebral hemisphere. Several of the findings were not described clearly in many of the standard textbooks of neurology. Weakness of sternomastoid when present was always contralateral to the hemiparesis. This emphasises the principle that the cerebral hemisphere controls movement of the body parts in or towards the contralateral half of the body rather than simply the contralateral muscle groups. An apparent exception to this was seen, however, in the small group of patients who had unilateral weakness of the tongue. In those patients deviation of the tongue was towards the hemiparetic side-that is, the cerebral hemisphere controlled the contralateral half of the tongue and hence protrusion towards the ipsilateral side. Mild dysarthria was common with both right and left sided hemiparesis.
\end{abstract}

\footnotetext{
Department of Medicine, Auckland University School of Medicine, and Department of Neurology, Auckland Hospital, New Zealand ERNEST W WILLOUGHBY, MB, FRACP, senior lecturer in neurology NEIL E ANDERSON, $M B, C H B$, senior registrar in neurology

Correspondence to: $\operatorname{Dr} \mathrm{E}$ W Willoughby, Department of Medicine, Auckland University School of Medicine, Private Bag, Auckland, New Zealand.
}

\section{Introduction}

Information on many aspects of dysfunction in the facial and bulbar musculature in patients with hemiparesis due to a cerebral hemisphere stroke is fragmentary and, in some cases, contradictory. Most of the statements in neurological textbooks on the subject are made without reference to published basic data. This study was undertaken to determine the frequency and characteristics of disturbances of motor functions supplied by cranial nerves V, VII, X, XI, and XII in patients with a clinical diagnosis of a unilateral cerebral hemisphere vascular lesion.

\section{Patients and methods}

We studied 100 hospital patients with hemiparesis or hemiplegia and a clinical diagnosis of a unilateral cerebral hemisphere vascular lesion. Fifty five of the patients were men and 45 women, and their ages ranged from 16 to 93 (median 69). Forty six had right sided weakness (20 with hemiparesis, 26 with hemiplegia) and 54 left sided weakness ( 21 with hemiparesis, 33 with hemiplegia). For this study the unilateral weakness was termed hemiparesis if the patient could dorsiflex the foot against gravity and hemiplegia if dorsiflexion was paralysed.

At the time of examination all patients had weakness of the arm and leg of at least moderate degree. In all cases the weakness developed suddenly (within 24 hours) with a subsequent plateau or improvement of the neurological deficit. The interval from the ictus to the time of examination ranged from one day to four and a half years, but most patients (70) were examined between one day and one month after the onset of symptoms; the median interval was 14 days.

Only patients able to cooperate with most of the cranial nerve examination were studied. Those who were drowsy or noticeably confused were excluded, as were patients with dysphasia severe enough seriously to limit communication, patients with bilateral neurological signs, or symptoms or signs suggesting a brain stem lesion, and patients with a history of neurological disease of any 